\title{
A emigração dos assistentes sociais portugueses: faces do trabalho e do desemprego em tempos de crise e austeridade*
}

\author{
The emigration of Portuguese social workers: faces of \\ work and unemployment in times of crisis and austerity
}



\author{
Alcina Maria Martins de Castro** \\ Rosa Maria Tomé**** \\ Virgínia Alves Carrara****
}

Resumo: A atual crise do capital imprimiu um ciclo de emigração aos diplomados portugueses. Não encontrando possibilidades de trabalho, licenciados, mestres e doutores buscam emprego, impelidos pela ideia de livre circulação dos cidadãos da União Europeia e pela internacionalização da formação superior com o Processo de Bolonha. A emigração dos diplomados portugueses é refletida como uma estratégia

* Investigação realizada no âmbito do Projeto Investigação, Formação e Trabalho em Serviço Social em Portugal e Brasil vinculado ao Centro de Estudos da População, Economia e Sociedade (Cepese), Porto, Portugal. Agradecemos a todos os assistentes sociais portugueses emigrantes que colaboraram nesta pesquisa.

** Assistente social, professora associada e coordenadora do pós-graduação em Serviço Social do Instituto Superior Miguel Torga (ISMT), Coimbra, Portugal. Doutora em Serviço Social com pós-doutoramento na Pontifícia Universidade Católica de São Paulo. Investigadora do Cepese/Porto, Portugal. Instituto Superior Miguel Torga. E-mail: alcina_martins@sapo.pt.

*** Assistente social, professora auxiliar do Programa de Pós-Graduação e da Licenciatura em Serviço Social do ISMT/Coimbra, Portugal. Doutora em Letras, especialidade História Contemporânea da Universidade de Coimbra. Investigadora do Cepese/Porto, Portugal. Instituto Superior Miguel Torga. E-mail: rosa_tome@hotmail.com.

**** Assistente social, professora adjunta II do Departamento de Ciências Sociais, Jornalismo e Serviço Social (DECSO), do Instituto de Ciências Sociais Aplicadas (ICSA) da Universidade Federal de Ouro Preto, Minas Gerais/Brasil. Realizando estágio de pós-doutoramento no ISMT/Coimbra, Portugal, com apoio da Capes. Universidade Federal de Ouro Preto.E-mail: vcarrara@icsa.ufop.br. 
do capital no recrutamento de força de trabalho qualificada e excedente e por parte dos trabalhadores no enfrentamento ao desemprego, em determinados países.

Palavras-chave: Crise do capital. Emigração dos assistentes sociais portugueses. Processo de Bolonha.

\begin{abstract}
The current economical crisis triggered a cycle of emigration among Portuguese graduates. Unable to find job opportunities, graduates, masters and doctors apply for jobs, impelled by the freedom of movement for citizens of the European Union and the internationalization of higher education with the Bologna Process. The Portuguese emigration of graduates is reflected as a capital strategy in recruiting skilled workforce and surplus work and by workers in facing with unemployment in some countries.
\end{abstract}

Keywords: Capital crisis. Emigration of Portuguese social workers. Bologna Process.

\title{
Introdução
}

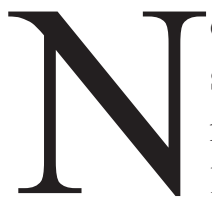

os variados meios de comunicação são difundidas notícias de uma saída sistemática de portugueses diplomados que rumam a outras nações capazes ainda de oferecer emprego. Verificam-se, na realidade, discursos que expressam a eminente fatalidade da saída. Por um lado, os recém-chegados ao ensino superior e, de forma mais intensa, os que se encontram em vésperas da obtenção da licenciatura, ${ }^{1}$ expressam preocupações, numa gradação que vai da revolta pela situação estão a cortar-nos as pernas, à perspectiva de sair da zona de conforto e até à posição de desenvolver algum voluntariado em outras paragens. Por outro lado, representantes do poder público incentivam a emigração, norteando os jovens a mostrar no estrangeiro o que Portugal tem de melhor. ${ }^{2}$ Encontramos ainda uma miríade de sítios de recrutamento com anúncios convidativos dirigidos aos potenciais

1. Este dado faz parte dos resultados parciais da pesquisa de pós-doutoramento $A$ imagem social construida e a atual autoimagem da profissão: diálogo entre as particularidades do Serviço Social português e o Serviço Social brasileiro em tempo de crise do capital, por Virgínia Alves Carrara, no ISMT, sob a supervisão da profa. dra. Alcina Martins, em 2013/2014, com bolsa de estágio da Capes.

2. Em Monteiro (2014) encontramos a afirmação de Cavaco Silva, "além da ligação afectiva", empenhem-se em "projetar Portugal no estrangeiro pela positiva", para "contribuir para corrigir alguma desinformação que existe sobre o nosso país" e "ajudar a melhorar a credibilidade", criando "condições para o investimento no país por parte de investidores estrangeiros", para o "crescimento económico em Portugal e para o aumento do emprego". 
candidatos à emigração, um verdadeiro mercado para todos os gostos e bolsos, com slogans como: Emigrar para o Reino Unido: em terras de sua majestade; Emigrar para o Luxemburgo: com destino ao grão-ducado; Emigrar para Alemanha: o motor econômico europeu; Emigrar para a Noruega: à conquista dos fiordes. ${ }^{3}$ Ao que parece, as duas formas clássicas de lidar com a escassez da força de trabalho - a formação e a imigração — ganham um toque de perfumaria ao negócio da mobilidade, do deslocamento no campo da emigração, em especial na Europa sem fronteiras, mas não somente.

Este artigo é resultado de um estudo sobre a atual mobilidade/emigração de assistentes sociais portugueses. Desenvolveu-se em duas frentes: uma de base bibliográfica e documental e outra com profissionais de Serviço Social imigrantes.

O referencial téorico-metodológico da teoria social crítica, conforme Marx (1996), possibilitou a passagem do que "apareceu", isto é da aparência ao desvelamento da sua lógica, da sua dinâmica, enfim da sua essência. Pensar essa realidade inscreveu-se no esforço de desnaturalizar a atual mobilidade/ emigração, desvelando os múltiplos determinantes que atravessam essa realidade e tomando como centrais dois fenômenos - o desemprego e o Processo de Bolonha - no contexto da crise do capital que impacta a educação e o trabalho profissional.

\section{Emigração: uma das faces do desemprego na Europa do Espaço Comum do Ensino Superior e Investigação}

Segundo o Instituto Nacional de Estatística (INE, 2013) a emigração de portugueses em 2012 foi de 121 mil, superior aos nascimentos (89 mil) e aos óbitos (107 mil). A movimentação migratória, que desde o final dos anos 1960 não se verificava com essas dimensões, foi seguida de uma mudança no perfil do emigrante: além dos nacionais com reduzida escolaridade e qualificação

3. Disponível em: <http://comoemigrar.net/>, <http://pt.trabalhar.com/emprego/fora de portugal $>$ e $<\mathrm{http}$ //cdp.portodigital.pt/emprego/oportunidades de trabalho-2/oportunidades de emprego-fora de portugal $>$. Acesso em: 6 mar. 2014. 
profissional, vão para fora parcelas da força de trabalho jovem, com formação superior. Esses movimentos estão presentes ao longo da história da humanidade, com processos que se distinguem no tempo e no espaço, mas no presente "a decisão de migrar é impulsionada, principalmente, pelo emprego/desemprego" (Tavares, 2012, p. 139).

A emigração dos diplomados portugueses é refletida na relação com a dinâmica do atual desemprego que atinge Portugal, que por sua vez tem centralidade nas profundas mudanças operadas na reorganização do trabalho a partir da acumulação flexível neoliberal (Harvey, 1996), com a correlata exigência de um outro padrão de qualificação profissional, com alterações nos contratos de trabalho, no sistema de proteção social e nos novos papéis socioeconômicos do Estado. Um novo perfil de trabalhador foi requerido, tendo em vista os avanços da robótica, microeletrônica, sob a égide do progresso científico e tecnológico contemporâneo. Da empregabilidade associada no nível de escolaridade passou-se, preferencialmente, ao licenciado moldado sob a aquisição de competências e habilidades para competir no mercado de trabalho da sociedade do conhecimento do século XXI, com redução no tempo da formação da força de trabalho qualificada, o que foi possível, na Europa, com o Processo de Bolonha.

Nos discursos dos impulsionadores dessa reforma dos sistemas de ensino superior, como critica Kurtz (2012), a sociedade até então não foi uma sociedade do conhecimento, e somente agora foi descoberto o verdadeiro conhecimento. Por outro lado, essa tão propalada qualificação pouco tem garantido a ocupação de postos de emprego compatíveis com o nível de escolarização. No quadro do atual mercado de trabalho, além do desemprego, encontramos uma tendência que é a disparidade entre as qualificações e a natureza das funções desempenhadas pelos profissionais.

A crise econômica de 2008 agravou a situação do desemprego que, desde os anos 1970, já agudizava a sua vulgar feição estrutural em todos os cantos onde o modo de produção capitalista se espraiou. Segundo o relatório Organização Internacional do Trabalho (OIT, 2014), o número de desempregados no mundo aumentou 5 milhões, em 2013, superando o total de 202 milhões de pessoas. Nesse ano, 23 milhões de trabalhadores abandonaram o mercado, e 
estima-se que até 2018 o número de pessoas em busca de trabalho aumentará em mais de 13 milhões. Ainda segundo o relatório, na região da União Europeia (UE), no segundo trimestre de 2013 registraram-se sinais de recuperação da atividade econômica, porém isto não se traduziu em empregos. Nas economias desenvolvidas e na UE encontravam-se 45,2 milhões de pessoas desempregadas, sendo que $18,3 \%$ eram jovens. Outra tendência identificada é a grande lacuna de emprego para os jovens adultos com idades entre 25 e 34 anos. Em países como a Grécia, Irlanda, Portugal e Itália, as perdas de emprego foram mais pronunciadas nessa faixa etária.

Nesse cenário sombrio, ainda que se preveja um lento declive até 2018, ao lado do desemprego, o trabalho flexível e o trabalho precarizado são impostos pela relação do capital com o trabalho e considerados, na atualidade, tendências universais "cuja emergência se relaciona com a reestruturação produtiva, e pelas atuais características da acumulação capitalista em tempos de mundialização financeira, custoprazismo dos lucros do Estado neoliberal e crise do movimento sindical" (Mota, 2013, p. 47). Ainda que o emprego flexível e/ou precário constituam processos organicamente vinculados e constantes da configuração do trabalho no tempo presente, os flexíveis são caracterizados pela flexibilidade derivada do aumento da produtividade e da rapidez dos processos decisórios, em face das demandas do mercado e das reengenharias de processo, impulsionadas pelas novas tecnologias (Mota, 2013, p. 47-49) e pela “compressão de tempo e do espaço", como destaca Harvey (1996).

Já nos trabalhos precários prevalece a instabilidade e a insegurança contratual materializada nos contratos temporários, a termo, por meio da prestação de serviços, geralmente vigentes em empresas subcontratadas, terceirizadas e quarteirizadas. Homens e mulheres, enfim trabalhadores, vendem a sua força de trabalho com a generalização do trabalho assalariado no modo de produção capitalista e, desde então, um excedente populacional tornou-se não somente necessário, como funcional ao capital. O exército industrial de reserva, "produto necessário da acumulação ou do desenvolvimento da riqueza com base no capitalismo" (Marx, 1996, p. 733), fornece ao capital material humano para a sua expansão, ao mesmo tempo em que mantém parte dos trabalhadores empregados. Hoje, estes têm diferentes modalidades de contratos de trabalho. A 
acentuada exploração do trabalho pelo capital tem expressão na regulação dos salários, nas perdas de direitos sociais e trabalhistas, na permanente ameaça de expulsão da força de trabalho dos meios de produção, na intensificação do ritmo de trabalho com a combinação de extração de mais-valia absoluta e relativa, exigindo dos trabalhadores mais trabalho adicional.

O desemprego, para Marx (1996), não é uma oscilação das leis naturais do mercado que naturalmente seriam equilibradas pela mão invisível, mas tem significação econômica estrutural na acumulação capitalista com a existência da superpopulação relativa. Em momentos de abertura de novos mercados, ter à disposição do capital força de trabalho suplementar é outra função dos desempregados ou parcialmente empregados, que se afiguram no mercado de trabalho como flutuante, latente, estagnado. Encontramos desde os aptos para o trabalho, mas em atividades degradantes, até aos indigentes e os incapazes para o trabalho, enquadrados no pauperismo (Siqueira, 2013, p. 172 -75).

No mercado de trabalho contemporâneo, o trabalho voluntário surge muito valorizado pelas empresas autodenominadas socialmente responsáveis, com a sua correlata responsabilidade social empresarial. ${ }^{4} \mathrm{O}$ voluntariado tem aparecido ideologicamente como um fator de empregabilidade. No discurso do mercado, um currículo que tenha essa atividade é visto positivamente no momento da seleção.

Assim, na realidade europeia emerge o Serviço de Voluntariado Europeu (SVE), constituindo-se num mercado de solidariedade dirigido aos jovens em diferentes áreas de intervenção, entre elas cultura, patrimônio, desporto, serviço social, proteção civil, ambiente etc.

Os estágios profissionais vêm também ganhando expressão enquanto resposta ao desemprego. Criados em Portugal, em 1997, foram vistos como mecanismos que beneficiavam os jovens licenciados no mercado de trabalho. Segundo o Instituto de Emprego e Formação Profissional (IEFP), entre 2001 e 2011 abarcaram 255 mil pessoas, das quais de $10 \%$ a $30 \%$ tiveram mais proba-

4. Sobre esta temática conferir em Carrara, Virgínia Alves. Responsabilidade social empresarial: intervenção social e conflito. Tese (Doutorado) - PUC-RJ, Departamento de Serviço Social, 2010. Disponível em: <http://www.maxwell.vrac.puc-rio.br/16545/16545_1.PDF>. Acesso em: 17 fev. 2014. 
bilidades de conseguir um emprego (Campos, 2014). Com a Portaria n. 92/2011, o estagiário foi equiparado a um trabalhador por conta de outrem, com uma bolsa mensal de estágio sujeita a taxa de Imposto sobre Rendimentos Singulares (IRS) e a descontos para a Segurança Social. A comparticipação do IEFP no valor da bolsa varia em função da natureza jurídica e da dimensão das entidades, sendo o valor para licenciados, mestres e doutores de 691,71 euros (Oliveira, 2012). A partir de 2013 os estágios empregos foram concebidos como "uma forma de transição para a vida ativa que não deve consistir na ocupação de um posto de trabalho" (Portaria n. 204-B/2013). Segundo Campos (2014), o estágio profissional (ou estágio emprego), não é mais do que "uma oportunidade para o vazio", uma precariedade permanente, a que está subjacente a "quimera do emprego, que arremessa no futuro a promessa de um contrato com direitos", inserindo-se na "lógica de uma valorização desqualificadora, na qual o acesso ao emprego se faz por uma antecâmara de concorrência e precariedade".

O desemprego visto como uma das múltiplas expressões da questão social ${ }^{5}$ é indissociável da realidade e da lógica do capital. Particulariza-se pelos determinantes sócio-históricos e pelo lugar que cada país ocupa no desenvolvimento do internacionalismo. ${ }^{6}$

\subsection{Mercado e cidadania na União Europeia: alguns elementos}

Criado pelo capitalismo, o mercado mundial, do qual a UE é expressão emblemática contemporânea com os seus organismos institucionais (Comissão Europeia, Banco Central Europeu, Tribunal de Justiça da União Europeia,

5. Questão social é aqui tomada na perspectiva de Iamamoto como "as expressões do processo de formação e desenvolvimento da classe operária e de seu ingresso no cenário político da sociedade, exigindo o seu reconhecimento como classe por parte do empresariado e do Estado. É a manifestação, no cotidiano da vida social, da contradição entre o proletariado e a burguesia, a qual passa a exigir outros tipos de intervenção, mais além da caridade e da repressão" (Iamamoto e Carvalho, 1982, p. 77).

6. Em Marx e Engels (1997, p. 32-33) encontramos: “A necessidade de um escoamento sempre mais extenso para os seus produtos persegue a burguesia por todo o globo terrestre. Tem de se implantar em toda a parte, instalar-se em toda a parte, estabelecer contactos em toda a parte. A burguesia pela sua exploração do mercado mundial configurou de um modo cosmopolita à produção e o consumo de todos os países. 
Conselho Europeu, Conselho da União Europeia, Parlamento europeu e Tribunal de Contas) fez emergir o cidadão europeu.

Considerado o mais ambicioso projeto político-econômico do Ocidente, a UE tem as suas raízes na busca pela construção da paz, após duas grandes guerras mundiais, controlando o mercado da grande indústria com a criação da Comunidade Europeia do Aço e do Carvão (CECA), além de buscar um equilíbrio entre os diferentes países com suas diferentes necessidades. Enfim, posicionando a Europa, sob a direção de uma alta autoridade comum, ligando a França e Alemanha e os países aderentes ao "princípio fundamental da transferência de poderes - transferência efetuada com plena liberdade por nações que delegam parte de sua soberania em instituições comuns, que a exercerão em seu nome" (Monnet, apud Poidevin, 1980, p. 516). Este processo foi iniciado com a participação de seis nações: França, Itália, Alemanha Federal, Bélgica, Holanda e Luxemburgo. Em 1956, com o Tratado de Roma, foi criado um mercado único de 180 milhões de europeus que, progressivamente, eliminou os obstáculos que se opunham à livre circulação de mercadorias, pessoas, empresas, serviços, capitais, enfim todos os fatores implicados com a produção (Poidevin, 1980, p. 519), sob a lógica expansionista do capital. A tessitura desta unidade econômico-política, numa Europa dividida — a do Oeste e a do Leste — culminou em 1992 com o Tratado de Maastricht com a criação da UE, constituída por três pilares: as comunidades europeias, a política externa e de segurança comum e a cooperação policial e judiciária em matéria penal, instaurando seis novos domínios de políticas comunitárias: redes transeuropeias, política industrial, defesa do consumidor, educação e formação profissional, juventude e cultura (Comissão Europeia, 2010). Com este Tratado emerge uma cidadania paralela, a cidadania europeia que confere novos direitos: de circular e residir livremente na Comunidade; de votar e ser eleito nas eleições europeias e municipais do Estado de residência; à proteção diplomática e consular de um Estado-membro diferente do Estado-membro de origem; a petição ao Parlamento Europeu e de apresentação de queixa junto do provedor de Justiça europeu.

$\mathrm{Na}$ arquitetura desse projeto estava o objetivo de uma constitucionalização da Europa que fracassou. Em 2009, entrou em vigor o Tratado de Lisboa, que dispôs sobre o funcionamento da UE, alterando o controle das imigrações 
(estabelecendo regras, condições e direitos em matéria de imigração legal) e criando o espaço europeu de investigação.

As regras de imigração na UE resultam de diretivas, o que significa que cada membro deve transpô-las para o seu direito nacional dentro de um prazo determinado. Desse modo, cada país decide autonomamente sobre: número total de migrantes que admite para efeitos de trabalho; decisões finais sobre pedidos de migração; regulamentação em matéria de vistos de longa duração — superiores a três meses; e os requisitos relativos à obtenção de autorizações de residência e trabalho, nos casos em que não tenham sido adotadas as regras comuns da UE. Nesse processo, foram limitados os anteriores obstáculos à entrada de força de trabalho do agora cidadão europeu, de trabalhador altamente qualificado e investidores de países terceiros. ${ }^{7}$

A urgência em ter condições para competir no mercado econômico exige alta tecnologia de informação e comunicação, e a ausência de força de trabalho altamente qualificada criou as bases para a criação do espaço europeu de investigação, numa sociedade em que o desenvolvimento econômico está atrelado ao domínio dessas tecnologias.

Segundo Cardoso (2002, p. 112), “a formação de blocos regionais como Nafta, UE e Mercosul trouxe consigo a atualização de problemas historicamente associados a fluxos migratórios". Numa economia que defende que a informação e o conhecimento substituiriam a dependência das economias industriais, tornou-se necessária a existência de trabalhadores qualificados e a constituição de um exército de trabalhadores diplomados de reserva, mal pagos, sem segurança e proteção nas condições de trabalho, prontos para ser descartados, deslocados e quem sabe alocados de acordo com os imperativos da mão invisível (Sevilla, 2010). Na competição euro-americana, resolver a questão da escassez

7. Comissão Europeia. Portal da Imigração da UE. Disponível em: <http://ec.europa.eu/immigration/ showContent.do?id=17056>. Acesso em: 10 mar. 2014. A Diretiva n. 2009/50/CE criou o Cartão Azul para regular a mobilidade de trabalhador altamente qualificado. Em Portugal, desde 2012, é permitida a entrada de investidores de países terceiros com os vistos dourados, desde que invista um montante igual ou superior a 1 milhão de euros, criem pelo menos dez postos de trabalho ou comprem imóveis no valor mínimo de 500 mil euros. Com o visto dourado, o investidor pode circular livremente no espaço Schengen, trabalhar sem restrições e se beneficiar do direito de reagrupamento familiar. 
da força de trabalho qualificada exigiu da UE um duplo esforço: reorganizar a imigração e a formação profissional.

\section{Serviço Social, o Processo de Bolonha e o trabalho profissional em Portugal no contexto da crise}

A Declaração de Bolonha (1999) construiu o caminho e a definição de qual educação e formação eram necessárias para o Mercado Comum Europeu e internacional, sob a lógica do capital, culminando em 2009 com a adesão de 46 países signatários ao Processo de Bolonha. Nesse sentido, permitir o livre trânsito de estudantes entre os diversos países desde os primeiros anos da formação superior, bem como certa liberalidade nos fluxos migratórios, vem possibilitando aos países mais bem posicionados economicamente competir na captação de força de trabalho numa economia assente no conhecimento, como acreditam os seus ideólogos.

Foi definido o tempo necessário para a formação superior com "qualidade" em relação aos espaços da sua utilidade: um primeiro ciclo útil para o mercado de trabalho europeu e um segundo ciclo, conducente ao grau de mestre, para desenvolvimento e aprofundamento dos conhecimentos obtidos no primeiro ciclo de estudos e para especializar para a investigação e para a profissão (Decreto-lei n.74/2006).

As ações previstas pelos Estados aderentes para a implementação de Bolonha, especialmente a "criação de um sistema de graus acadêmicos facilmente reconhecíveis e comparáveis", não vem possibilitando o reconhecimento automático dos diplomados que pretendam exercer a profissão em outro país.

O Serviço Social é uma das oitocentas profissões que estão submetidas ao regime geral do reconhecimento de títulos de formação, segundo a Diretiva n. 2005/36/CE. A avaliação do impacto de Bolonha relativamente ao reconhecimento das qualificações profissionais efetuada ao abrigo dessa Diretiva (Study evaluating the Professional Qualifications Directive against recent educational reforms in EU Member States, 2011), na área da educação e da formação, contemplou oito profissões, de entre elas o Serviço Social, em dezessete países. 
No conjunto dos Estados-membros da UE, a profissão é regulamentada em dezoito países, com exceção da Bélgica, Chipre, Dinamarca, Hungria, Países Baixos, Suécia e Portugal.

Onde a profissão é regulamentada é exigido aos assistentes sociais um conjunto de procedimentos, que varia de país para país, mas sempre são necessários dois processos: o do diploma e a autorização para o exercício profissional. Para o primeiro, devem apresentar toda a documentação exigida, devidamente traduzida e certificada. Para a autorização para o exercício profissional devem, junto ao órgão regulador da profissão, apresentar: diploma reconhecido, competência linguística comprovada, prova de aptidão (um teste que incida sobre conhecimentos, aptidões e competências profissionais do requerente, realizado ou reconhecido pelas autoridades competentes do Estado-membro de acolhimento), estágio profissional com prática supervisionada por um profissional e um docente, credenciados por um organismo nacional. Para os dois processos são cobradas taxas.

O reconhecimento da profissão constitui um enorme desafio. As perspectivas sobre o Serviço Social são muito diferentes, com implicações na formação e no exercício profissional, nomeadamente na compreensão e importância atribuída à relação teoria/prática, segundo o estudo supracitado. Na Alemanha, por exemplo, o Serviço Social tem o status de ciência, enquanto noutros países têm componentes ancorados na psicologia e na pedagogia. As configurações sociopolíticas, jurídicas e institucionais dos Estados-membros são também elementos da diversificação das demandas historicamente colocadas à profissão. Para o processo de reconhecimento, a autoridade competente é em geral um Ministério - da Saúde, da Educação — ou, como no caso da Itália, o Ministério da Justiça. Em outros países, estão envolvidos outros corpos específicos, como na Espanha, o Conselho Geral de Ação Social, e na Itália, o Conselho Nacional da Ordem dos Assistentes Sociais.

A fim de "reforçar o mercado interno e promover a livre circulação de profissionais garantindo ao mesmo tempo, um reconhecimento das qualificações mais eficiente e transparente", a Diretiva n. 2013/55/EU do Parlamento europeu e do Conselho definiu a criação de uma carteira profissional europeia com vista a "facilitar a mobilidade temporária e o reconhecimento ao abrigo do regime 
de reconhecimento automático, bem como para promover um processo de reconhecimento simplificado no âmbito do regime geral".

\subsection{Serviço Social e Processo de Bolonha: formação da força de trabalho sob a lógica do mercado}

No âmbito da formação e do trabalho profissional, a década de 1990 foi prodigiosa para a expansão do Serviço Social português. O reconhecimento do grau acadêmico, em 1989/90, atingiu os três únicos institutos privados de formação, sendo fundamental para a criação da carreira técnica superior de Serviço Social, em 1991. Ao mesmo tempo, institucionalizou-se a formação pós-graduada com os cursos de mestrado em Serviço Social, ${ }^{8}$ abriu-se a carreira acadêmica aos assistentes sociais, criaram-se as primeiras organizações de investigação (Associação de Investigação e Debate em Serviço Social - AIDSS, Centro Português de Investigação em História e Trabalho Social - CPIHTS), acrescendo as produções acadêmicas. Esse reconhecimento processa-se no contexto do Estado social, com a integração de Portugal na Comunidade Econômica Europeia, que financiou, sobretudo o desenvolvimento de programas sociais de apoio aos Estados-membros, com ênfase na luta contra a pobreza, para os quais era necessário recrutar e formar assistentes sociais. Nesse sentido, a expansão dos cursos de Serviço Social nos anos 1990, ocorre exclusivamente em IES privadas, indo ao encontro dessa nova demanda. Se até 1992 se diplomaram em Portugal 4540 assistentes sociais (Martins e Tomé, 2008, p. 162), em média 84 ao ano, entre 1993 e 2003 formaram-se 433 ao ano (Martins, 2008, p. 34).

Na entrada do século XXI, prossegue a expansão da formação, com destaque para o ensino público nos subsistemas universitário e politécnico, mas que se processa sem regulamentação. A ausência de diretrizes comuns para a formação profissional, num cenário em que não foi consubstanciado o projeto profissional gestado no processo de luta pela licenciatura, conduziu a uma diversidade de planos de estudos, de componentes curriculares, com diferenças

8. A pós-graduação mestrado e doutorado na área iniciam-se com um convênio entre a PUC-SP e o ISSSL (1986), vindo a ser reconhecidos os cursos criados em Portugal em 1995 e 2003, respectivamente. 
na duração das licenciaturas, e ausência de exigências quanto a qualificação acadêmica da coordenação científica e docência em Serviço Social nos novos cursos. As licenciaturas, no ensino universitário, eram realizadas em cinco anos, mas em 2004, sob a perspectiva da Declaração de Bolonha foram reduzidas para quatro. No ensino politécnico, a formação em Serviço Social surge associada a um bacharelato de três anos, vindo a licenciatura bietápica a ser concluída com mais um ano, colocando em causa o patamar anterior da formação. Tudo isto resultou numa multiplicidade de perfis profissionais.

Os cursos públicos de Serviço Social trazem, desde a primeira hora, as marcas da precarização com um quadro docente diversificado e tendencialmente sem doutorados na área, alguns com contrato a tempo integral, outros recrutados da administração pública, para exercerem funções docentes sem integrar a carreira acadêmica, e ainda outros, que não sendo da área, lecionam disciplinas específicas do Serviço Social. Os cursos de doutoramento em Serviço Social são criados a partir de 2003 e, os seus correspondentes centros de investigação, sem que o Serviço Social seja reconhecido como área científica pela Fundação para a Ciência e Tecnologia (FCT), o que permanece até hoje. Acresce que as comissões de avaliação de projetos e atribuição de bolsas de estudos e investigação continuam a não integrar especialistas e investigadores do Serviço Social.

A adesão de Portugal à reforma do ensino superior europeu - Bolonha — acentua a fragilidade na formação profissional ao determinar a redução dos anos de curso com a introdução dos ciclos de estudos. O processo de adequação da formação ao sistema de Bolonha decorreu entre os anos letivos de 2006/2007 e 2008, no quadro de uma ampla autonomia por parte das 21 instituições formadoras, sem referências a diretrizes comuns da área para a definição dos planos de estudo. O registro de adequação dos planos curriculares foi efetuado junto da Direção Geral do Ensino Superior (DGES), vindo, posteriormente, a Agência de Avaliação e Acreditação do Ensino Superior (A3ES) criada pelo Decreto-lei n. 369/2007, a avaliar os ciclos de estudos em funcionamento e as propostas de novos cursos. Para tanto, foi criada uma comissão de especialistas em Serviço Social em 2011, com doutores desta área, reconhecendo as suas especificidades no âmbito científico-acadêmico. Esta nova prerrogativa é um elemento a potenciar o fortalecimento do coletivo dos assistentes sociais em direção à construção de diretrizes e parâmetros formativos, bem como adensar 
a luta pela defesa da regulamentação da profissão, contribuindo para o debate e a estratégia política da categoria.

A redução do tempo de formação minimizou os conteúdos da dimensão teórico-metodológica e ético-política, com ênfase na dimensão técnico-operativa de cariz pragmático, baseado no desenvolvimento de competências, para adequá-las às solicitações do mercado de trabalho, também ele em transformação. Nessa lógica, a formação vem, tendencialmente, respondendo às demandas técnico-administrativas das atuais políticas focalistas, assistencialistas e emergenciais.

2.2 Trabalho dos assistentes sociais: (des)emprego e (e/i)migração

Também para o recrutamento de assistentes sociais como força de trabalho especializada, os anos 1990 foram impactantes. De acordo com Pires, entre 1991 e 1999, o mercado de trabalho dos assistentes sociais no setor público contou com "691 concursos, com 1.478 vagas para técnicos superiores de Serviço Social (TSSS), distribuídos pela Administração Pública Central, 436 concursos e 1.132 vagas e pela administração pública local com 255 concursos e 346 vagas" (Pires, 2009, p. 53). Hoje o cenário é outro. Com a reforma da administração pública de 2008, os técnicos superiores em carreiras específicas transitaram para a carreira geral de técnico superior. Assim, foi extinta a carreira de TSSS. O acesso aos concursos passou a ficar disponível para licenciados das áreas das ciências sociais e humanas, e só em situações particulares, pode haver indicação de preferência para os titulares da licenciatura em Serviço Social.

A partir de 2010 foram suspensos os concursos públicos em curso e foi congelada a abertura de novos concursos já no contexto da crise do capital. No ano seguinte, no bojo de uma crise política e financeira interna, Portugal acaba por se submeter aos imperativos das agências de financiamento externa - Comissão Europeia, Banco Central Europeu e Fundo Monetário Internacional intensificando as medidas de austeridade como: cortes nos vencimentos e pensões, redução do número de dirigentes e funcionários públicos, corte do valor das indenizações por despedimento no setor privado, corte nos subsídios de doença e desemprego, aumento dos impostos, aumento da jornada de trabalho, 
redução de feriados e de dias de férias e alargamento dos bancos de horas, aumento dos impostos sobre os rendimentos do trabalho, corte no financiamento da saúde e no setor dos medicamentos, com aumento das taxas moderadoras pagas nos serviços públicos de saúde, aumento dos preços da energia e gás, cortes orçamentais em todos os níveis de ensino (básico, secundário e superior), encerramento de serviços públicos da justiça, saúde, educação, medidas essas que consolidaram os processos de privatização com o agravamento do desemprego e do empobrecimento da população portuguesa.

Com a chegada da Troika, em 2011,

o número de portugueses no limiar da pobreza têm aumentado de uma forma contínua, representando, em 2012, já 18,7\% da população total, o que significa que 1.961 .100 portugueses vivem já na miséria [...] sem prestações sociais, o número de portugueses que estaria no limiar da pobreza subiria para 4.918.500, o que corresponderia a 46,9\% da população total (Rosa, 2014).

De acordo com o Observatório das Desigualdades (2014) e dos registros do INE, de 2007 a 2013, 656 mil pessoas perderam emprego e mais de 427 mil encontravam-se desempregadas. O ano de 2013 é o que tem menor número de população empregada, 4.514 milhares, e o maior número de desempregados, 876 milhares. Em dezembro de 2013, encontravam-se desempregados 146,5 mil licenciados, e mais da metade já era de longa duração, isto é, desempregados há mais de um ano (Portugal, 2014). Mantendo a tendência do país, os assistentes sociais têm vindo a registrar crescentes taxas de desemprego. Entre 1983 e 2011 formaram-se 12.544, dos quais 165 mestres e cinco doutores. Estavam à procura do primeiro ou de novo emprego 1.618 (20 mestres e um doutor) e, destes, 539 (33,3\%) eram desempregados já de longa duração. ${ }^{9}$ Em apenas quatro anos (2009-12) esse valor atingiu os 894, ou seja, mais de metade dos desempregados registrados em quase três décadas.

Os registros oficiais escamoteiam a real situação de desemprego, seja porque os diplomados se inserem no trabalho informal, temporário e precário,

9. IEFP/DGEES: Desemprego dos Diplomados, dez. 2013. 
ou em formação profissional, seja tão só por não verem benefícios na inscrição no IEFP. Conforme Martins (2010), em finais dos anos 1990, o desemprego dos assistentes sociais em Portugal era residual. A partir de meados da primeira década do século XXI deixa de ser. A situação socioprofissional dos assistentes sociais, tanto dos empregados como dos desempregados, tem vindo a agravar-se nos últimos anos.

A tendência de mudança nas relações e condições de trabalho dos profissionais foi identificada, a partir de 2007, no Concelho de Tomar, por António (2009). Apesar de prevalecer o contrato sem termo, já se assinalavam novas modalidades de emprego precário na profissão: contratos a tempo certo, recibos verdes, estágio profissional, existindo maiores dificuldades em aceder a uma carreira profissional estruturada. A carga horária de trabalho era de 35 horas, mas já se começavam a registrar situações de uma carga horária superior, chegando mesmo a ultrapassar às quarenta horas semanais. Quanto ao salário auferido, era inferior ao previsto na legislação em vigor relativa à carreira TSSS. A diferença salarial entre o setor público e o privado não lucrativo era de duzentos euros, nomeadamente nas Instituições Particulares de Solidariedade Social (IPSS), no início da carreira profissional. O salário de um assistente social em part time no setor privado lucrativo era menos de quatrocentos euros por mês. Nos anos que antecederam a extinção da carreira TSSS, já se assistia ao congelamento da sua progressão (António, 2009, p. 32-69).

Diante desse cenário com trabalhos precários, perdas progressivas de direitos sociais, empobrecimento, desemprego gerando inseguranças e sem perspectivas de mudança em curto prazo, têm levado muitos licenciados a buscarem na emigração a alternativa para sair desta situação.

A informação sobre o número de emigrantes portugueses diplomados é escassa, dispersa e incompleta, mas de acordo com a Organização para a Cooperação e Desenvolvimento Econômico (OCDE), Portugal tem as taxas mais altas do chamado brain drain, com cerca de $20 \%$ dos diplomados a saírem do país, como destacam Amaral e Marques (2013).

Até o momento não se tem conhecimento de dados estatísticos e/ou investigações e estudos que deem conta da emigração dos diplomados em Serviço Social em Portugal. Entre 2009-10 e 2011-12, licenciaram-se 4.552 no conjunto 
dos cursos que integram a área do Trabalho Social e Orientação ${ }^{10}$. Destes, 1.402 encontravam-se registrados como desempregados, ${ }^{11}$ e $664{ }^{12}$ mostraram-se disponíveis para trabalhar no estrangeiro, em dezembro de 2013.

Não foi fornecido, pelo setor responsável do IEFP, o número correspondente de assistentes sociais desempregados a emigrar. Podemos, contudo, referir que, de 2012 para 2013, o número de diplomados em Serviço Social desempregados sofreu um decréscimo de 894 para $779 .{ }^{13}$ Nos bancos de dados oficiais não foi possível encontrar outros indicadores estatísticos que permitissem identificar qual a sua situação face ao trabalho: empregados na área, fora da área, a fazer formação, estágio profissional, ou se emigraram.

Se internamente os assistentes sociais têm enfrentado os constrangimentos impostos pelas medidas de austeridade, enquanto emigrantes dispostos a trabalhar como assistentes sociais no estrangeiro, os desafios não são menores. Bolonha e as "facilidades" para a imigração não significaram imediato emprego para os diplomados, ainda que existam vagas no país de destino. Obrigados a sair, a porta de entrada ao que parece não se encontra assim tão aberta no país de acolhimento.

\section{Processo migratório dos assistentes sociais portugueses}

Buscando conhecer elementos do processo de emigração dos assistentes sociais no contexto da crise e do desemprego no país, desenvolveu-se um estudo exploratório de natureza qualitativa. Localizamos, nas redes sociais, treze assistentes sociais portugueses a residir no estrangeiro, que vieram a constituir

10. A área do Trabalho Social e Orientação integra o seguinte elenco de cursos de primeiro ciclo: Serviço Social, Animação Sociocultural, Animação Socioeducativa, Animação Cultural e Educação Comunitária, Educação Social, Educação Social e Desenvolvimento Comunitário, Educação Social e Gerontológica, Educação Socioprofissional, Gerontologia Social, Aconselhamento Psicossocial, Reabilitação e Inserção Profissional, Animação e Intervenção Sociocultural, Intervenção Comunitária de acordo com as estatísticas do ensino superior do INE.

11. IEFP/DGEES: Desemprego dos Diplomados, dez. 2013.

12. Informações fornecidas pela Direção de Serviços de Estudos, Planeamento e Controlo de Gestão do IEFP/Lisboa em 11/3/2014.

13. IEFP/DGEES: Desemprego dos Diplomados, abr. 2014. 
o grupo privilegiado dos interlocutores. ${ }^{14}$ De acordo com os princípios éticos na investigação, foi feito o convite para participarem voluntariamente nesse estudo e, simultaneamente, solicitada a autorização para utilização das suas respostas.

$\mathrm{Na}$ primeira fase, foi-lhes enviado um questionário que nos permitiu identificar os elementos de natureza sociodemográfica, a trajetória da formação, as possibilidades de acesso ao trabalho e ao exercício da profissão, as motivações e os custos do processo de emigração, bem como os países onde residem e trabalham como emigrantes. Na segunda fase, solicitamos alguns esclarecimentos complementares, que constituíram verdadeiros relatos da experiência socioprofissional antes e após a emigração e o respectivo balanço que fazem desse processo.

A maioria dos asssistentes sociais colaboradores nessa investigação são mulheres, com idades compreendidas entre 25 e 38 anos, solteiras, que terminaram a licenciatura entre 2003 e 2011. Emigraram, na sua maioria sozinhas, para países membros da UE (Dinamarca, Luxemburgo, Reino Unido e Alemanha), para a Suíça, para a América do Norte (Canadá e Estados Unidos), para África (Moçambique e São Tomé e Príncipe) e para a Austrália.

Fizeram a formação em IES universitárias (privadas e públicas) e politécnicas (pública). Registra-se que oito fizeram o curso antes da adequação da formação ao Processo de Bolonha, com duração de cinco e quatro anos e três fizeram o primeiro ciclo, com duração de seis e sete semestres. Antes de emigrarem três eram mestres em Serviço Social e uma era mestranda no âmbito do European Erasmus Mundus in Social Work.

Identificamos dois períodos no processo emigratório: o primeiro a partir de 2008 e o segundo depois de 2011. O primeiro coincide com o contexto da crise financeira mundial, conforme referido anteriormente e com o primeiro surto migratório dos diplomados portugueses das mais distintas áreas do conhecimento. Simultaneamente, no caso do Serviço Social, assistimos ainda à extinção da carreira TSSS e aos milhares de recém-diplomados a pressionar o mercado de trabalho, que, não encontrando emprego vão constituir um excedente de força

14. Dois não foram contemplados na análise: um não respondeu e outro foi utilizado como pré-teste. 
de trabalho especializada na área do Serviço Social. O esgotamento do emprego no setor público e o bloqueio que se manifesta nas IPSS e noutras organizações similares, fruto do desmonte contínuo do Estado social, gera um enorme contingente de desempregados que iniciam o seu percurso de precariedade, primeiro ainda no contexto da área profissional, depois, muito rapidamente, no quadro do emprego fora da área.

O segundo período, a partir de 2011, corresponde ao aumento significativo do processo migratório dos assistentes sociais, à semelhança do que se passou em nível nacional. No bojo da crise política e financeira em Portugal, com as medidas de austeridade impostas pela Troika, intensificou-se a deterioração das condições de vida e de trabalho da população portuguesa. Paralelamente, a formação com o Processo de Bolonha disponibilizou para o mercado de trabalho num período de tempo mais curto um volume maior de diplomados, que, mesmo prosseguindo para o segundo ciclo, continuavam a não encontrar emprego.

A decisão de emigrar do grupo em estudo radicou na inexistência de emprego na área e na ausência de perspectivas, a curto e médio prazos, de trabalho com garantia de segurança, proteção social no exercício da profissão e progressão na carreira. Observa-se que nem o mercado de trabalho absorveu os diplomados do primeiro ciclo, nem o segundo ciclo deu garantias de emprego. Verificamos duas vias de emigração por parte do grupo estudado: a da formação e a do trabalho. Na primeira via estão os que partiram em busca de qualificação acadêmica: um saiu como bolseiro de doutoramento em Serviço Social por um período de quatro anos e outro saiu no quadro da mobilidade no âmbito do Programa Erasmus. Quanto à via do trabalho, identificamos três trajetórias: os que encontraram trabalho profissional; os que estão a trabalhar fora da área; os que se inseriram em programas de voluntariado, um dos quais, para ter possibilidade de acesso ao trabalho profissional, ingressou num curso de mestrado.

$\mathrm{Na}$ análise do como foi esse processo de saída, encontramos as fragilidades do que foi anunciado como vantagem para a mobilidade profissional no espaço europeu do ensino superior e da investigação, com o Processo de Bolonha. A discussão a seguir apreende o processo de emigração: o acesso e as condições de trabalho em Portugal; os trâmites e procedimentos requeridos para trabalhar no país de destino, com destaque para os reconhecimentos da 
qualificação (diploma, exercício profissional); as condições de trabalho e formação enquanto imigrante.

\subsection{Acesso e condições de trabalho em Portugal}

O IEFP, na última década, passou a constituir-se como mais uma estratégia na procura de emprego para os recém-licenciados de Serviço Social. Finda a formação, a maioria dos assistentes sociais participantes da investigação inscreveu-se no IEFP, sem no entanto obter êxito: nem conseguiram emprego em Portugal, nem apoio no processo de emigração. Só um contactou com um conselheiro Eures, ${ }^{15}$ cujo contributo se reduziu a facultar a consulta de listas de possibilidades de emprego no espaço europeu. Apenas uma minoria exerceu a profissão em Portugal, em IPSS(s) e numa organização humanitária internacional. Nenhum trabalhou em serviços públicos, da administração central ou local. Cinco trabalharam fora da área do Serviço Social em atividades como: call center, serviços de estética, recepção de hotel e outros, registrando-se uma grande rotatividade nos contratos e serviços.

Quatro assistentes sociais fizeram estágio profissional, com duração entre quatro e doze meses; apenas um teve oportunidade de realizar um segundo estágio, num serviço público (Direcção Regional de Educação), após a conclusão do mestrado em Serviço Social. Os únicos (dois) que não fizeram estágio profissional nem voluntariado, terminaram o curso em 2003. Sete fizeram voluntariado, cinco dos quais em Portugal em instituições como Santa Casa da Misericórdia de Lisboa, Banco Alimentar contra a Fome, Cáritas, Fundação Gil, Legião da Boa Vontade e Associação Portuguesa de Apoio à Vítima (Apav), estes concluíram a licenciatura depois de 2008.

No que respeita às condições de trabalho - tipo de contrato, horário, salário, férias, proteção na saúde e segurança social —, somente um trabalhou

15. Eures é a rede europeia de serviços de emprego que visa facilitar a mobilidade dos trabalhadores a nível transnacional e transfronteiriço, no âmbito do Espaço Econômico Europeu (EEE) (os 28 Estados-membros da União Europeia, a Noruega, Liechtenstein e a Islândia) e Suíça — uma área que integra atualmente 32 países. Disponível em: <https://www.iefp.pt/eures>. Acesso em: 22 mar. 2014. 
com contrato sem termo, outro trabalhou em regime de prestação de serviços, e os demais, tiveram contratos a termo certo, dentro e/ou fora da área da sua formação. Relativamente ao trabalho na área, a duração do contrato variou entre seis meses e três anos. Os estágios profissionais tiveram uma duração máxima de um ano. O horário de trabalho situava-se entre 35-40 horas semanais, inclusive nos estágios. No caso da prestação de serviços (recibos verdes), o tempo de trabalho era de 20 horas semanais. Um assistente social trabalhava 60h/semana, no cargo de direção técnica de uma IPSS. Os salários dos que exerceram a profissão variavam entre quinhentos e oitocentos euros mensais, valor inferior ao estabelecido no contrato coletivo de 2012. ${ }^{16}$ Apenas quatro tiveram direito a férias remuneradas e cinco foram beneficiários da segurança social. Dos que realizaram trabalho de voluntariado em Portugal, registramos que nenhum teve direito a qualquer pagamento pelas horas de trabalho realizadas - entre 1 hora e 36 horas semanais. Três assistentes sociais foram integrados no Serviço de Voluntariado Europeu (SVE), que cobre custos de viagem, alojamento, alimentação, seguro e processo formativo, com direito a dinheiro de bolso (cerca de 280 euros), dependente do custo de vida do país de acolhimento. Nem o estágio profissional nem o voluntariado constituíram passagem para o emprego, permanecendo esses assistentes sociais na antecâmara da concorrência e precariedade do trabalho em Portugal.

O balanço que fazem da sua condição de licenciado, estagiário e/ou trabalhador até saírem do país, tem expressão nas seguinte afirmações:

A luta por uma condição minimamente estável é tão cansativa que dá vontade de desistir da profissão (2).

Poucas perspetivas de evolução na carreira, fracos salários e muitas responsabilidades, sem possibilidades de evoluir ao nível da formação por conta da entidade empregadora (3).

Infelizmente o meu país nunca me deu oportunidade de trabalhar na minha área (8).

16. Os salários definidos pelo contrato coletivo de 2012 estabelecido entre a Confederação Nacional das Instituições de Solidariedade (CNIS) e a Federação Nacional de Educação (FNE) e outros variavam entre 1.015 e 917 euros (Boletim do Trabalho e Emprego, n. 6, 15 fev. 2012). 
Até sair de Portugal, acredito que embora a minha motivação fosse muita, visto ter iniciado logo após terminar o curso a especialização e pós-graduação, as condições de trabalho não foram as ideais. Como assistente social e directora de um lar para idosos, o salário era pouco mais do que o salário mínimo e idêntico ao de uma auxiliar. O salário era de quinhentos euros/mês e só folgava ao domingo... e muitas vezes só meio dia. [...] e responsável por toda a gestão do mesmo. Sinto que, enquanto assistente social em Portugal o meu percurso foi progressivo mas não estimulante, visto que enquanto assistente social, as minhas condições de trabalho e remuneração eram piores do que enquanto operadora de call center (11).

\subsection{0 processo de emigração e 0 acesso ao trabalho profissional}

Os que emigraram enfrentaram um longo caminho que exigiu recursos financeiros, sociais, linguísticos e legais. Nos países onde o Serviço Social é regulamentado acresce ainda a necessidade do reconhecimento do diploma e a autorização para o exercício profissional. Quanto aos custos do processo de emigração: viagem (passagens, passaportes e vistos no caso de países fora da UE), instalação (alojamento) e recursos de subsistência até a inserção no mercado de trabalho, os valores informados pelos participantes da pesquisa variaram entre quinhentos e 10 mil euros. Essas despesas foram condicionadas pela distância do país de destino, seu custo de vida, acrescidas pelo tempo de espera da autorização para o exercício profissional. Os processos mais onerosos foram os da Austrália, Moçambique e Canadá. Dentro da UE, o mais dispendioso foi o da Alemanha. Os assistentes sociais que saíram pela via do voluntariado (SVE) tiveram alguns custos para providenciar o passaporte e o certificado de residente na UE (montante declarado 92 euros). Os que contaram nos primeiros tempos com o apoio de familiares, amigos e da comunidade portuguesa no país de destino tiveram despesas de instalação e alojamento reduzidas, especialmente nos casos de longos processos de reconhecimento do diploma e a autorização para o exercício profissional.

10 mil euros... toda a minha poupança. Foi para fazer o visto de estudante, pagar o agente de emigração e o primeiro semestre do curso... com o objectivo da 
certificação australiana com vista à residência permanente no final (curso de dois anos custo total de 30 mil dólares australianos [cerca de 19.500 euros] viagem só de ida para os dois foi de mil euros... estadia três dias numa residencial de jovens 120 dólares australianos...agora são de duzentos dólares australianos [cerca de 130 euros] por semana numa casa partilhada com tudo pago (considerado muito pouca renda comparado com a média de 350 a 400 por semana). Apoios... Somente nós os dois (8).

Quanto ao reconhecimento das qualificações, a grande surpresa recaiu sobre os (e)imigrantes na UE e países signatários do Processo de Bolonha, pois as equivalências não são automáticas. Percebe-se que há uma tendência de aproximadamente um ano para conclusão dos processos de reconhecimento, mas alguns são mais morosos, conforme nos é expresso pelos assistentes sociais:

Na Suíça temos que fazer o pedido ao Office Fédéral de la Formation Professionnelle et de la Technologie - OFFPT. Tive que apresentar os conteúdos dos programas para cada disciplina do curso [...] devidamente traduzido numa das três línguas nacionais. Tive também que apresentar um certificado de francês do nível B1 e claro pagar todo o processo [...]. [O processo demorou] mais ou menos um ano. Não me recordo quanto é que gastei ao todo, mas como temos que ter tudo traduzido por alguém que é reconhecido, eu mandei fazê-lo na Alliance Française em Coimbra. Penso ter pago cerca de 1.500 euros [...]. Depois temos também que pagar para dar entrada do processo em Berne. E finalmente temos que pagar cerca de duzentos francos, para fazer uma formação de 3 dias em Lausanne, onde basicamente explicam onde podemos procurar as leis que nos interessam e como funcionam as administrações cantonais e federais. [...] No final fazemos teste, mas nada muito complicado. O que é mesmo necessário é pagar [...]. Desde que estou aqui, já pude ver que nem todos passam por este processo, pois se concorrerem para um cargo numa associação privada, pode não ser exigido o reconhecimento. Mas eu optei pelo seguro (3).

Numa primeira fase: diplomas do 12. ano e da licenciatura traduzidos para alemão e um currículo. Numa segunda fase: um estágio profissional com supervisão. A supervisão é efectuada por um professor de um Instituto Superior acreditado para o efeito (informação dada pelo Bezirksregierung de Arnsberg [Alemanha]). Tive que procurar um local para estagiar e mensalmente tinha reuniões de supervisão. 
Esses encontros não eram apenas para profissionais com qualificações obtidas no estrangeiro, mas também para recém-licenciados alemães. Por ser um grupo misto, foi interessante a troca de experiências. [...] A primeira fase durou aproximadamente um ano. [...] A demora deveu-se em grande parte às organizações portuguesas $[\ldots]$. A segunda fase (estágio) durou um ano. Em suma, o reconhecimento académico demorou aproximadamente dois anos (9).

Em África, nomeadamente em Moçambique e São Tomé e Príncipe, como a profissão não é regulamentada, só o diploma dá acesso ao exercício profissional. Em países fora da UE e onde a profissão é regulada, como no caso da Austrália, os procedimentos são morosos e complexos, como se pode ver na seguinte fala:

Aqui há muita burocracia. É necessário fazer um exame de inglês chamado IELTS exigindo um valor de $7 \mathrm{em}$ todos os componentes (não o consegui por meio ponto), não farei outro exame porque é necessário muito dinheiro. Aqui funciona de duas maneiras. Teremos que traduzir nossas qualificações por um tradutor registrado da Austrália e carimbado por um “juiz de paz” (aqui juiz de paz é a polícia), de seguida ir à universidade fazer por seis meses equivalências (devido a diferenças culturais e legislativas); ou por outro lado, tentar a inscrição na Associação de Assistentes Sociais e eles farão por nós as traduções reconhecidas, equivalências e teremos trabalho logo de seguida. Porém é muito dinheiro que se gasta aqui. A solução mais fácil é tentar um sponser alguém ou associação que nos queira como assistentes sociais por dois anos consecutivos (8).

Estes processos são dispendiosos e podem não ser exitosos na primeira tentativa. $\mathrm{O}$ assistente social tem de dispor de reserva financeira para fazer frente às exigências e ao tempo de espera, que pode ser longo, requerendo novas estratégias de sobrevivência através da procura de trabalho em outras áreas, que não da sua formação e até mesmo realizando prosseguimento de estudos. O caso emblemático é o da Dinamarca:

Procurei o centro de emprego em Copenhaga e solicitei um profissional para ajuda de procura de emprego e inserção e recorri a uma instituição não governamental para ter uma tutoria [...] na minha área, que me ajudasse informalmente 
com alguma informação para o meu futuro profissional e pessoal na Dinamarca. O sistema dinamarquês é de difícil acesso, não por exigir requisitos especiais ao assistente social, mas pela língua que é muito difícil de aprender. Para nos ajudar nesse processo a profissional do centro de emprego estabelece connosco uma estratégia que pode passar por trabalhar em algo distinto, para adquirir competência linguística, de modo a podermos "dar o salto" para a nossa área de formação. Esta profissional considera que o mestrado que estou a realizar é um investimento positivo e por isso o meu caso estará em pausa até que o termine. Quando o fizer, volto a contactá-la para estabelecer um novo plano, visto que o que tínhamos traçado anteriormente não faz sentido com esta nova formação. Isto faz-me sentir um apoio que não sinto em Portugal, e apesar das dificuldades com o idioma, já consegui realizar alguns projectos com instituições locais e sinto que a formação é valorizada (4).

\subsection{Trabalho e formação do assistente social imigrante}

A maioria dos que saíram em busca de trabalho encontra-se atualmente empregada na área de Serviço Social. Dois receberam convite para trabalhar em Moçambique: um para a docência universitária em Serviço Social e outro para a coordenação de um centro médico de natureza privada. Dos restantes, um está em formação, outro permanece em programas de voluntariado, e dois trabalham fora da área, sendo que um já progrediu no trabalho, ocupando o cargo de assistente de gerente, enquanto decorre o seu processo de reconhecimento.

Quanto às condições de trabalho na área de Serviço Social, três têm contratos sem termo em países europeus (Suíça, Luxemburgo e Alemanha) e outros tantos têm contrato a termo certo, em países africanos (Moçambique e São Tomé e Príncipe). Registra-se que apenas um trabalha num serviço público com progressão na carreira, encontrando-se a realizar o curso de mestrado numa IES portuguesa. O horário de trabalho é, em média, de 40h, mas encontram-se variações entre as 30 e as 48 horas semanais. Um está a fazer doutoramento em Serviço Social no Canadá, como atividade principal, onde também exerce a docência na área. O que saiu ao abrigo do Programa Erasmus já se encontra a exercer a profissão e a realizar um segundo mestrado numa IES em Portugal. 
Relativamente às condições de vida e trabalho, a maioria afirmou ter proteção na saúde e segurança social e uma minoria tem cobertura de outros riscos, nomeadamente com seguros opcionais. Uma tem proteção na maternidade, e cerca de metade refere usufruir de férias remuneradas. Na Alemanha e na Suíça, as entidades empregadoras asseguram formação contínua aos assistentes sociais.

$\mathrm{O}$ balanço e as expectativas traçadas pelos assistentes sociais interlocutores são expressas nas seguintes falas:

Penso que me ajudou a crescer profissionalmente. É uma experiência muito positiva (3).

Não me considero emigrante, mas sim um estudante, investigador/trabalhador qualificado a residir temporariamente no país de frequência do programa de doutoramento. $\mathrm{O}$ balanço tem sido muito positivo, pois permitiu alargar os horizontes em termos multiculturais e linguísticos, bem como desenvolver outras competências e conhecimentos ao nível do Servico Social, que em Portugal não seria possível (5).

Não quero acreditar que serei emigrante para sempre, [...]. Custa-me saber que estudei, estudei e estudei, para neste momento olhar para trás e pensar: foi "quase" tudo em vão. E fico pensando, quando será que vou poder exercer novamente a minha profissão no meu país? Será amanhã?, será para o ano?, ou nunca mais será? Resumindo, se eu gosto de ser emigrante? Não, não gosto (7).

Sinto uma enorme revolta por ter sido "obrigada" a abandonar o meu país para trabalhar. Sou uma estrangeira na Alemanha, e quando regresso a Portugal, sinto-me também estrangeira. Ser emigrante num país como Alemanha não é fácil (9).

\section{Considerações finais}

A saída massiva de profissionais com formação superior em busca de emprego com segurança e garantias sociais é uma realidade nova nos processos emigratórios de portugueses, imposta pela lógica do capital na Europa sem fronteiras e do espaço comum do ensino e da investigação.

Os assistentes sociais não ficaram incólumes aos impactos da crise do capital: seja com o desmonte do Estado social, a redução e focalização das 
políticas públicas e a redefinição do acesso aos direitos sociais, seja com a extinção de postos de emprego e aumento do desemprego. Ao mesmo tempo (re)criaram-se modalidades de contrato e de condições de trabalho (recibos verdes, contrato a termo, estágio profissional, o voluntariado e até a sua reedição no nível internacional, baixa de salários e fragilização dos direitos laborais) que se configuram como alternativas precárias de trabalho para os diplomados.

O discurso da mobilidade profissional dirigido ao cidadão europeu com as suas correlatas possibilidades de trabalho, neste estudo exploratório, revelou-se falacioso para os assistentes sociais, licenciados e mestres. A reforma da educação superior com Bolonha e a uniformização dos ciclos de estudo não se revela como garantia, ou mesmo facilitadora dos processos de reconhecimento acadêmico e de emprego. Nem a profissão é automaticamente reconhecida na UE, nem é considerada uma das profissões estrategicamente valorizadas pela "economia do conhecimento". A emigração como estratégia de enfrentamento ao desemprego e ao trabalho precário dos assistentes sociais portugueses processa-se, no país de destino, por duas vias autoimplicadas: trabalho e qualificação acadêmica. Aos assistentes sociais emigrantes foi-lhes imposto uma série de procedimentos, como cursos, formação complementar, estágios supervisionados, avaliações, que demandam tempo e dinheiro. O processo complexificou-se nos países em que profissão é regulamentada, exigindo, além do reconhecimento acadêmico, a autorização para o exercício profissional.

A Diretiva n. 2013/55/UE do Parlamento europeu e do Conselho procede da revisão e modernização da de 2005, acima citada, cuja transposição para o direito de cada país terá lugar até 2016, com vista à simplificação do processo de reconhecimento das qualificações, nomeadamente com a criação da carteira profissional europeia. Em 2011 a Fias-Europa foi consultada pelo DG Internal Market and Services para se pronunciar sobre a proposta de revisão desta Diretiva relativamente às qualificações do social work. Referindo-se à Recomendação do Comitê de Ministros dos Estados-membros para os social workers, de 2001, a Fias-Europa afirma, em 2011, a necessidade de o social work se tornar uma profissão regulamentada em todos os Estados-membros, uma vez que "it is to be noted that mobility may be more limited in countries that are not regulated" (Fias, 2011, p. 5). 
A não regulamentação da profissão constitui-se em mais um elemento que fragiliza não só a condição da formação, do trabalho e da organização dos assistentes sociais portugueses em tempos de desmonte do Estado social e austeridade, como impacta o próprio processo de emigração, em tempos de crise do capital.

Recebido em 11/9/2014 - Aprovado em 24/11/2014

\section{Referências bibliográficas}

AMARAL, Susana; MARQUES, Ana Paula. Emigração portuguesa de profissionais altamente qualificados: uma proposta de leitura a partir do discurso jornalístico e das perspetivas de atores envolvidos. Braga: CICS, Universidade do Minho, 2013 Disponível em: <http://www.fes-web.org/uploads/files/modules/congress/11/papers/2211. pdf $>$. Acesso em: 4 fev. 2014.

ANTÓNIO, Tânia. Mercado e condições de trabalho dos assistentes sociais no Concelho de Tomar. Dissertação (Mestrado em Serviço Social) — Instituto Superior Miguel Torga, Coimbra, 2009. Disponível em: <http://repositorio.ismt.pt/handle/123456789/198>. Acesso em: 9 fev. 2014.

CAMPOS, Adriano. Estágio: oportunidade ou precariedade permanente? Disponível em: <http://inflexaoblog.blogspot.pt/search/label/Adriano\%20Campos $>$. Acesso em: 23 mar. 2014.

CARDOSO, Arnaldo Francisco. Migrações internacionais: os blocos regionais e a mobilidade mundial de mão de obra. São Paulo em Perspectiva, v. 16, n. 2, p. 112-124, 2002. Disponível em: <http://dx.doi.org/10.1590/S0102-88392002000200013>.

COMISSÃO EUROPEIA. Síntese da Legislação da UE. Disponível em: <http://europa. eu/legislation_summaries/institutional_affairs/treaties/treaties_maastricht_pt.htm. 2010. Acesso em: 15 jan. 2014.

FIAS-EUROPA. Disponível em: < http://ec.europa.eu/internal_market/consultations/2011/professional_qualifications_directive/professional-organisations/ifsw_ en.pdf $>$. Acesso em: 10 abr. 2014. 
HARVEY, D. Condição pós-moderna: uma pesquisa sobre as origens da mudança cultural. São Paulo: Loyola, 1996.

HOWAT, Colin; ULICNA, Daniela; HARRIS, Paul. Final Report: study evaluating the professional qualifications directive against recent educational reforms in EU member States (revised). Londres: GHK, 2011.

IAMAMOTO, Marilda; CARVALHO, Raul de. Relações sociais e Serviço Social no Brasil: um esboço de uma interpretação histórico-metodológico. São Paulo: Cortez, 1982.

INE. Estatísticas Demográficas 2012. Disponível em: <http://www.ine.pt/xportal/ xmain?xpid=INE\&xpgid=ine_publicacoes\&PUBLICACOESpub_boui $=151772777 \&$ PUBLICACOESmodo=2>. Acesso em: 4 fev. 2014.

KURTZ, Robert. A ignorância da sociedade do conhecimento: o estágio final da evolução intelectual moderna será uma macaqueação de nossas mais triviais ações por máquinas? 2012. Disponível em: $<$ http://obeco.planetaclix.pt/robertkurz.htm>. Acesso em: 25 mar. 2014.

MARTINS, Alcina. Formação e mercado de trabalho em Serviço Social, nos últimos 20 anos em Portugal. In: CONGRESSO NACIONAL DE SERVIÇO SOCIAL, 2., Almada, 2010.

. Investigação em Serviço Social no Portugal contemporâneo: paradoxos e desafios.Locus Soci@l, revista de Serviço Social, política social e sociedade, Lisboa, n. 1, p. 32-47, 2008.

; TOMÉ, Rosa. Formação contemporânea do Serviço Social em Portugal. Em Pauta, Rio de Janeiro, n. 21, p. 153-169, 2008.

MARX, Karl. O capital. São Paulo: Nova Cultural, 1996. t. 1, v. 1.

; ENGELS, Friedrich. O Manifesto do Partido Comunista. 2. ed. Lisboa: Avante, 1997.

MONTEIRO, Sandra. A emigração forçada. Le Monde Diplomatique, Lisboa, n. 87, jan. 2014. Disponível em: $<$ http://pt.mondediplo.com/spip.php?page=article-print\&id article $=969>$. Acesso em: 23 mar. 2014.

MOTA, Ana Elizabete. Trabalho precário na indústria de confecções: apontamentos sobre a realidade brasileira e a portuguesa. Em Pauta, Rio de Janeiro, $1^{\circ}$ sem. 2013. 
OBSERVATÓRIO DAS DESIGUALDADES. Disponível em: $<$ http://observatorio-das-desigualdades.com/2014/03/17/a-evolucao-do-desemprego-em-portugaltaxa-de-desemprego-em-2013-e-a-mais-alta-da-ultima-decada/>. Acesso em: 5 abr. 2014.

OIT. Global employment trends 2014: risk of a jobless recovery? Disponível em: $<$ http:// www.ilo.org/wcmsp5/groups/public/---dgreports/---dcomm/---publ/documents/publication/wcms_233953.pdf>.Acesso em: 25 fev. 2104.

OLIVEIRA, Alexandre. Medidas ativas de emprego. Apoio ao empreendorismo. IEFP, 2012. Disponível em: <http://ec.europa.eu/portugal/pdf/comissao/9maio_2012/apresentacoes/apresentacao_medidas_ativas_emprego_alexandre_oliveira_iefp_pt.pdf $>$. PIRES, Susana. Mercado de trabalho em Serviço Social no setor público em Portugal nos anos 90. Dissertação (Mestrado em Serviço Social) — Instituto Superior Miguel Torga, Coimbra, 2009. Disponível em: $<$ http://repositorio.ismt.pt/handle/123456789/193>. Acesso em: 5 dez. 2013.

POIDEVIN, Raymond et al. História geral da Europa III: a Europa desde 1789 aos nossos dias. Mem Martins: Publicações Europa-América, 1980.

PORTUGAL. Portal direito do trabalho. 2014. Disponível em: <http://www.portal-direito-do-trabalho.pt/33/licenciados-sem-trabalho-ha-mais-de-um-ano-crescem-ate-81 mil-uniqueidjXNs71B4Pu0RsYdWdUuUTkD6PtcoZC2J/?query=licenciados + sem + tr abalho+a+mais + de\&serp=1>. Acesso em: 23 mar. 2014.

ROSA, Eugênio. Miséria e desigualdades crescem em Portugal. 2014. Disponível em: $<$ http:/www.oribatejo.pt/wp-content/uploads/2014/04/15-Miseria-aumenta-Portugal. pdf $>$. Acesso em: 12 jun. 2014.

SEVILLA, Carlos. La fábrica del conocimiento: la universidad-empresa en la producción flexible. El Viejo Topo: Ediciones de Intervención Cultural, 2010.

SIQUEIRA, Luana. A leitura marxista sobre a pobreza. A outra face da acumulação capitalista. In: MONTAÑO, Carlos; BASTOS, Rogério (Orgs.). Conhecimento e sociedade: ensaios marxistas. São Paulo: Outras Expressões, 2013. p. 165-85.

TAVARES, Maria Augusta. Imigração e Imigrantes em Portugal: o Estado de todos existe para cada um? In: VARELA, Raquel (Org.). Quem paga o Estado social em Portugal? Lisboa: Bertrand, 2012. 